\title{
Awareness of osteoporosis among 368 residents in China: a cross-sectional study
}

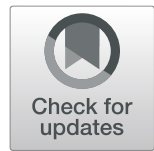

Kemal Sherefa Oumer, Yawen Liu, Qiong Yu, Fan Wu and Shuman Yang*

\begin{abstract}
Background: Studies on osteoporosis awareness among the general population in China are still limited. We examined the level of osteoporosis awareness among residents in China, determined the risk factors associated with a lower level of osteoporosis awareness, and assessed the sources of their knowledge about osteoporosis.

Methods: We conducted a cross-sectional study among 368 general residents aged 30 years or older from 19 provinces during January-March 2018 in China. All participants were identified and interviewed face-to-face by medical students in Jilin University using a structured questionnaire. Osteoporosis awareness scores (percent of the correct answer) were determined across several domains, including definition, diagnosis, risk factors, and prevention of osteoporosis. We used multiple linear regression models to test the relationship between risk factors and overall awareness scores.

Results: The mean age of included participants was $52.9 \pm 10.2$ years, and $53 \%$ of them were male. Osteoporosis awareness score for definition was $77.7 \%$, diagnosis $49.6 \%$, risk factors $49.2 \%$, treatment $60.5 \%$, and prevention $69.9 \%$. The overall awareness score was $67.8 \%$. Lower family income and education level were significantly associated with lower overall awareness score (all $p<0.05$ ). Television or radio health program was reported to be their main source of knowledge about osteoporosis.

Conclusion: The awareness level for osteoporosis in our study is moderate; lower family income and education level were risk factors for lower awareness. Television or radio health programs had the greatest contribution to osteoporosis awareness.
\end{abstract}

Keywords: Osteoporosis, Awareness, Knowledge, China

\section{Background}

Osteoporosis characterized as low bone mass and microarchitectural deterioration is a major public health problem. It is estimated to affect 200 million women worldwide and cause more than 8.9 million fractures annually [1]. By 50 years of age, one in three women and one in five men will suffer a fracture in their remaining lifetime [2]. It is projected that by $2050,50 \%$ of hip fractures will occur in Asia, with the majority occurring in China [3]. Osteoporosis affects almost 7.0 million

\footnotetext{
* Correspondence: shumanyang@jlu.edu.cn

Department of Epidemiology and Biostatistics, School of Public Health, Jilin University, 232-1163 Xinmin Street, Changchun 130021, Jilin, China
}

Chinese over the age of 50 and causes about 687,000 hip fractures in China each year [4]. Improving osteoporosis awareness is useful for controlling this problem because a high level of osteoporosis awareness increases the possibility of early osteoporosis detection and promotes effective osteoporosis prevention and treatment $[5,6]$.

Although there are several Chinese studies that have examined osteoporosis awareness [7-12]. Studies on osteoporosis awareness among the general population in China are still limited. Also, no studies have determined the risk factors associated with lower levels of osteoporosis awareness and assessed the way of source of knowledge about osteoporosis. Therefore, we examined the level of osteoporosis awareness among residents in

(c) The Author(s). 2020 Open Access This article is licensed under a Creative Commons Attribution 4.0 International License, which permits use, sharing, adaptation, distribution and reproduction in any medium or format, as long as you give appropriate credit to the original author(s) and the source, provide a link to the Creative Commons licence, and indicate if changes were made. The images or other third party material in this article are included in the article's Creative Commons licence, unless indicated otherwise in a credit line to the material. If material is not included in the article's Creative Commons licence and your intended use is not permitted by statutory regulation or exceeds the permitted use, you will need to obtain permission directly from the copyright holder. To view a copy of this licence, visit http://creativecommons.org/licenses/by/4.0/ The Creative Commons Public Domain Dedication waiver (http://creativecommons.org/publicdomain/zero/1.0/) applies to the data made available in this article, unless otherwise stated in a credit line to the data. 
Table 1 Characteristics of study $(N=368)$

\begin{tabular}{|c|c|}
\hline Characteristics & Values \\
\hline Male (n, \%) & $195(53)$ \\
\hline \multicolumn{2}{|l|}{ Age group (years) } \\
\hline $30-49(n, \%)$ & $208(56.5)$ \\
\hline $50-59(n, \%)$ & $76(20.7)$ \\
\hline $60-69(n, \%)$ & $55(14.9)$ \\
\hline Above $70(n, \%)$ & $29(7.9)$ \\
\hline Body mass index $\left(\mathrm{kg} / \mathrm{m}^{2}\right)$ & $23.7(3.3)$ \\
\hline \multicolumn{2}{|l|}{ Residence } \\
\hline Urban $(n, \%)$ & $166(45.1)$ \\
\hline Rural (n, \%) & $113(30.7)$ \\
\hline Suburban (n, \%) & $89(24.2)$ \\
\hline \multicolumn{2}{|l|}{ Education } \\
\hline Primary and below (n, \%) & $69(18.8)$ \\
\hline Junior ( $n, \%)$ & $113(30.7)$ \\
\hline Senior $(n, \%)$ & $84(22.8)$ \\
\hline Graduate (n, \%) & $102(27.7)$ \\
\hline \multicolumn{2}{|l|}{ Family annual income (US dollar) } \\
\hline$<1400(\mathrm{n}, \%)$ & $41(11.1)$ \\
\hline 1400-6999 (n, \%) & $128(34.8)$ \\
\hline 7000-13,999 (n, \%) & $97(26.4)$ \\
\hline$\geq 14,000(n, \%)$ & $102(27.7)$ \\
\hline Prior bone mineral density test $(n, \%)$ & $68(18.5)$ \\
\hline Prior fracture (n, \%) & $48(13)$ \\
\hline \multicolumn{2}{|l|}{ Smoker } \\
\hline Current (n, \%) & $68(18.5)$ \\
\hline Past (n, \%) & $45(12.2)$ \\
\hline Never $(n, \%)$ & $255(69.3)$ \\
\hline Alcohol user (n, \%) & $133(36.1)$ \\
\hline
\end{tabular}

Values are means (SD), unless otherwise specified

China, determined the risk factors associated with a lower level of osteoporosis awareness, and assessed the sources of their knowledge about osteoporosis.

\section{Methods}

\section{Study setting and population}

This cross-sectional survey was conducted from 19 provinces during January-March 2018 in China. The inclusion criteria for the survey participants were 1) aged 30 years or older at the interview; 2) able to give consent to participate in the study, and 3) capable of understanding and answering the questions. The participants were identified and interviewed face-to-face by medical students in Jilin University (Enrolment year: 2017; Specialty: Preventive Medicine) using a structured questionnaire. The participants for this survey included the relatives, friends, and neighbours of the students. Before conducting the survey, all medical students were trained to identify suitable participants and conducting the survey with a structured questionnaire in a face-to-face meeting room by related researchers. This study was approved by the Ethical Committee Board at the School of Public Health, Jilin University. Each participant also provided written informed consent to this study.

\section{Study measures}

Socio-demographics (sex, age, body weight, height, residence, education level, and family annual income), lifestyle information (smoking, alcohol use), prior fracture and prior bone mineral density test were collected using a structured questionnaire. Height and weight were selfreported. Body mass index (BMI) was calculated as body weight $(\mathrm{kg})$ divided by squaring of body height $\left(\mathrm{m}^{2}\right)$. Educational level was classified as primary and below (Years of education: 6 and below), junior (Years of education: 7-9), senior (Years of education: 10-12) and undergraduate and postgraduate educations (Years of education: 13 and above). A residence was classified as urban, rural and suburban.

We assessed osteoporosis awareness level using the following domains, including by definition, diagnosis, signs/symptoms, treatment, complications, prognosis, causes, risk factors, and prevention of osteoporosis; the questionnaire about osteoporosis awareness was the same as previously published research [13]. The reliability and validity of the questionnaire was tested among 30 Chinese subjects before the formal survey. This questionnaire had good internal consistency (Cronbach's $\alpha=0.746)$. Under the factorial validity test, the related components explained a cumulative $60 \%$ of the variance in the awareness scores. The Kaiser-Meyer-Olkin measure of sampling adequacy and Bartlett's test of sphericity both showed that the results were suitable for factor analysis. Besides the osteoporosis awareness questions, we also collected the sources of the participants acquiring their existing osteoporosis knowledge (e.g., newspapers and magazines, advertising leaflets, television or radio health program).

\section{Statistical analysis}

We used descriptive statistics to describe the characteristics of the study population and the main variables. Continuous variables were shown as mean \pm standard deviation (SD); categorical variables were shown as percentages.

Awareness scores were created by assigning a "1" to each correct response and a "0" to each incorrect or "unsure" response. Awareness scores for all questions were summed for a possible range of 0 to 29 ; higher scores 
Table 2 Frequencies and percents of correct response by domain $(N=368)$

\begin{tabular}{|c|c|c|}
\hline Domain & $\begin{array}{l}\text { Domain score (\%) } \\
\text { (Correct response: } \mathrm{T}=\text { True, } \mathrm{F}=\text { False) }\end{array}$ & $\begin{array}{l}\text { Correct response, } \\
N(\%)\end{array}$ \\
\hline \multirow[t]{4}{*}{ Definition of Osteoporosis } & Osteoporosis is a condition of easy joint dislocation (F) & $222(60.3)$ \\
\hline & Osteoporosis is a condition of low bone mineral density $(T)$ & $296(80.4)$ \\
\hline & Osteoporosis is a condition of high bone mineral density (F) & $340(92.4)$ \\
\hline & Domain score $=77.7 \%$ & \\
\hline \multirow[t]{3}{*}{ Diagnosis of Osteoporosis } & Osteoporosis is diagnosed using $\mathrm{X}$-ray of the bone (T) & $192(52.2)$ \\
\hline & Osteoporosis is diagnosed with physical exam (F) & $173(47.0)$ \\
\hline & Domain score $=49.6 \%$ & \\
\hline \multirow{4}{*}{$\begin{array}{l}\text { Common signs/ symptoms } \\
\text { of osteoporosis }\end{array}$} & Headache is a common sign/symptom of osteoporosis (F) & $310(84.2)$ \\
\hline & Frequent fractures is a common sign/symptom of osteoporosis ( $T$ ) & $312(84.8)$ \\
\hline & Mood change is a common sign/symptom of osteoporosis (F) & $313(85.1)$ \\
\hline & Domain score $=84.7 \%$ & \\
\hline \multirow[t]{4}{*}{ Treatment of osteoporosis } & Osteoporosis can be treated with calcium and vitamin D (T) & $321(87.2)$ \\
\hline & Osteoporosis can be treated with surgical correction (F) & $273(74.2)$ \\
\hline & Osteoporosis can be treated with hormone replacement ( $\mathrm{T}$ ) & $74(20.1)$ \\
\hline & Domain score $=60.5 \%$ & \\
\hline \multirow[t]{4}{*}{ Complications of osteoporosis } & Diabetes is a complication of osteoporosis (F) & $313(85.1)$ \\
\hline & Hypertension is a complication of osteoporosis (F) & $310(84.2)$ \\
\hline & Hip fracture is a complication of osteoporosis ( $T$ ) & $311(84.5)$ \\
\hline & Domain score $=84.6 \%$ & \\
\hline \multirow[t]{3}{*}{ Prognosis for Osteoporosis } & Osteoporosis can lead to joint swelling and morning stiffness (F) & $162(44.0)$ \\
\hline & Osteoporosis can lead to hip fractures and subsequent complications (T) & $286(77.7)$ \\
\hline & Domain score $=60.8 \%$ & \\
\hline \multirow[t]{4}{*}{ Common causes of Osteoporosis } & Overweight is a common cause of osteoporosis in women (F) & $225(61.1)$ \\
\hline & Lack of estrogen is a common cause of osteoporosis in women (T) & $156(42.4)$ \\
\hline & High protein diet is a common cause of osteoporosis in women (F) & $263(71.5)$ \\
\hline & Domain score $=58.3 \%$ & \\
\hline \multirow[t]{4}{*}{ Risk factors for Osteoporosis } & Low rice intake is a risk factor for osteoporosis in women (F) & $233(63.3)$ \\
\hline & Post menopause is a risk factor for osteoporosis in women ( $T$ ) & $158(42.9)$ \\
\hline & Smoking is a risk factor for osteoporosis $(\mathrm{T})$ & $152(41.3)$ \\
\hline & Domain score $=49.2 \%$ & \\
\hline \multirow{4}{*}{$\begin{array}{l}\text { Risk of osteoporosis over a } \\
\text { woman's lifetime }\end{array}$} & Women are at highest risk for osteoporosis at puberty (F) & $315(85.6)$ \\
\hline & Women are at highest risk for osteoporosis during their childbearing ages (F) & $244(66.3)$ \\
\hline & Women are at highest risk for osteoporosis after menopause $(T)$ & $248(67.4)$ \\
\hline & Domain score $=73.1 \%$ & \\
\hline \multirow[t]{5}{*}{ Prevention of Osteoporosis } & Moderate physical exercise can reduce the risk of osteoporosis ( $T$ ) & $272(73.9)$ \\
\hline & Increased rice consumption can reduce the risk of developing osteoporosis (F) & $276(75.0)$ \\
\hline & $\begin{array}{l}\text { A diet rich in calcium and vitamin D can reduce the risk of developing } \\
\text { osteoporosis (T) }\end{array}$ & $306(83.2)$ \\
\hline & Cigarette smoking cessation can reduce the risk of developing osteoporosis ( $T$ ) & $175(47.6)$ \\
\hline & Domain score $=69.9 \%$ & \\
\hline
\end{tabular}

suggest greater awareness. The domain scores were an average of the percentages of correct answers to all questions under each domain.
To test the relationship between risk factors and overall awareness scores, we used multiple linear regression models. Covariates included sex, age, body mass index, 
Table 3 The associations between risk factors and overall awareness score in the multivariable linear regression models

\begin{tabular}{llll}
\hline Variables & $\beta$ & SE & $P$ value \\
\hline Male vs Female & -0.598 & 0.464 & 0.198 \\
Age in year & 0.008 & 0.019 & 0.676 \\
Body mass index $\left(\mathrm{kg} / \mathrm{m}^{2}\right)$ & 0.108 & 0.057 & 0.060 \\
Residence & & & \\
$\quad$ Urban vs Rural & 0.651 & 0.543 & 0.231 \\
$\quad$ Suburban vs Rural & -0.292 & 0.547 & 0.595 \\
Education level & & & \\
$\quad$ Junior vs Primary and below & 1.551 & 0.568 & 0.007 \\
$\quad$ Senior vs Primary and below & 2.333 & 0.644 & 0.000 \\
$\quad$ Graduate vs Primary and below & 1.857 & 0.693 & 0.008 \\
Family annual income (US dollar) & & & \\
$\quad<1400$ vs $\geq 14,000$ & -1.171 & 0.549 & 0.039 \\
$\quad$ 1400-6999 vs $\geq 14,000$ & -1.243 & 0.537 & 0.021 \\
$\quad$ 7000-13,999 vs $\geq 14,000$ & -1.136 & 0.532 & 0.033 \\
Prior BMD test vs No prior BMD test & 0.555 & 0.498 & 0.266 \\
Prior fracture vs No prior fracture & -0.850 & 0.560 & 0.130 \\
Smoker & & & \\
Current vs Never & -1.067 & .703 & 0.130 \\
Past vs Never & -0.581 & 0.659 & 0.378 \\
Alcohol user vs No alcohol user & 1.021 & 0.535 & 0.057 \\
\hline Abbrevatons: $\beta$ regresion coeffient, sE stand & & &
\end{tabular}

Abbreviations: $\beta$ regression coefficient, SE standard error, BMD bone mineral density

$P$ significant at $\leq 0.05$

residence, educational level, family annual income, prior bone mineral density test, prior fracture, smoking, and alcohol use.

All statistical analyses were performed by using SPSS software (version: 25.0; SPSS Inc., Chicago, IL).

\section{Results}

In total, we collected 372 questionnaires; each student returned an average of six survey questionnaires. Among

Table 4 Percent for each source for obtaining existing osteoporosis knowledge

\begin{tabular}{ll}
\hline Source & Percent \\
\hline Newspapers and magazines & 29.1 \\
Advertising leaflets & 11.1 \\
Community public paper material & 15.2 \\
Community health knowledge lecture & 15.8 \\
Television or radio health program & 55.7 \\
Internet & 22.6 \\
Wechat group & 29.1 \\
Chatting with friends and family members & 40.5 \\
None & 10.1 \\
\hline
\end{tabular}

372 questionnaires, four of them were excluded because of missing all data on osteoporosis awareness questions. We finally included 368 valid questionnaires in our analysis (Table 1). The mean age of included participants was $52.9 \pm 10.2$ years; $53 \%$ were males; the average BMI was $23.7 \pm 3.3 \mathrm{~kg} / \mathrm{m}^{2}$. Approximately, 18.5 and $36 \%$ of participants reported being current smokers and alcohol users, respectively.

\section{Osteoporosis awareness level}

Table 2 presents descriptive data about osteoporosis awareness scores by domain. Osteoporosis awareness score for definition was $77.7 \%$, diagnosis $49.6 \%$, risk factors $49.2 \%$, treatment $60.5 \%$, and prevention $69.9 \%$. The overall awareness score was $67.8 \%$.

Table 3 indicates that lower family income and education level were significantly associated with lower overall awareness scores (all $p<0.05$ ). However, all the other variables were not significantly associated with overall scores of osteoporosis awareness.

With regard to sources of knowledge about osteoporosis, television or radio health program was reported to be their main source of knowledge about osteoporosis (Table 4).

\section{Discussion}

In China, osteoporosis is still a major public health problem with a growing aging population. Raising osteoporosis awareness among the general population is useful for osteoporosis prevention and treatment programs [14]. This study examined the level of osteoporosis awareness among Chinese residents, determined the risk factors associated with a lower level of osteoporosis awareness, and assessed the sources of their knowledge about osteoporosis. We restricted participants aged 30 years or older because bone loss normally begins at that age and assessing osteoporosis awareness for these people is useful for more effective osteoporosis prevention and treatment [15-17].

In this study, the overall osteoporosis awareness score was $67.8 \%$; $83.3 \%$ of the respondents knew correctly aware of the definition of osteoporosis. These figures are higher than a study in Vietnam in which participants answered $49 \%$ of the knowledge questions correctly [13]. This discrepancy may be because our study participants have a higher education level than the Vietnamese participants (With graduated education: $27.7 \%$ vs. $19.4 \%$, respectively). Because most of the other studies used different questionnaires for assessing osteoporosis awareness [18-20], we can only compare the osteoporosis definition of awareness between studies. The studies in South Australia, Canada, and Greece found that 62$96 \%$ of participants correctly aware of the osteoporosis definition. These results are comparable to our study. 
Regardless of consistent and inconsistent results, our study found a low awareness score of the osteoporosis risk factors. In our study, one in every two participants did not know the risk factors and the diagnosis. This figure is much higher than a South American study, in which one in every ten participants did not know the osteoporosis risk factors [21]. This is likely attributed to the fact that the participants in the South American study have higher risk of osteoporosis than those in our study (Mean age: 63.0 vs. 52.9 years; percent for prior fracture: $49 \%$ vs. $13 \%$, respectively), and higher osteoporosis risk has been suggested to be positively associated with osteoporosis awareness [12].

It is generally believed that osteoporosis awareness level is greater in females than in males. This is not consistent with our study, in which females and males have comparable osteoporosis awareness levels. In our study, males have a better education than females in our study (Percent with graduated education: $33.8 \%$ in males vs. $20.8 \%$ in females; $P<0.001$ ); this may lead to similar osteoporosis awareness scores between sexes.

Our results showed a higher level of education was associated with better awareness of osteoporosis; this was also found in other studies [12, 22]. Individuals with better education may have a greater willingness to obtain osteoporosis-related knowledge.

In our study, $55.7 \%$ of participants reported television or radio health program as their main source of osteoporosis knowledge. The main source of knowledge was also a television for the Canadian, Singaporean, and American studies [20, 22, 23]. This provides an important and effective way of disseminating osteoporosis knowledge to the general population.

Our study has an advantage and two limitations. Although the questionnaire about osteoporosis awareness has been used in a previous study, we still validated the questionnaire prior to the formal survey. Our reliability and validity test results suggested the questionnaire is suitable for the present study. This study included only 368 participants; a small sample size has limitations to represent the general Chinese population. Lastly, due to cross-sectional design, we are unable to make causal inferences about the association between osteoporosis awareness score and related factors.

\section{Conclusions}

The awareness level for osteoporosis in our study is moderate; lower family income and education level were risk factors for lower awareness. Television or radio health programs had the greatest contribution to osteoporosis awareness. These findings may be useful for osteoporosis prevention and treatment among the general Chinese population. For example, future osteoporosis educational programs may include more information on osteoporosis risk factors.

\section{Abbreviations}

BMD: Bone mineral density; BMI: Body mass index; SD: Standard deviation; SPSS: Statistical package for the social sciences

\section{Acknowledgements}

Not applicable.

\section{Authors' contribution}

The authors made the following contributions: K.S.O., S.Y., and Y.L made the conception for this research. K.S.O. analyzed the data and drafted the article. Q.Y., F.W., and S.Y. reviewed/ edited the manuscript. All the authors critically revised the article for important intellectual content. S.Y. contributed to the study design and managed the overall project. The author(s) read and approved the final manuscript.

\section{Funding}

No funding was obtained for this study.

\section{Availability of data and materials}

The datasets used and/or analysed during the current study are available from the corresponding author on reasonable request.

\section{Ethics approval and consent to participate}

This study was approved by the Ethical Committee Board at the School of Public Health, Jilin University (Approval No: 2018-03-05). Each participant also provided written informed consent to this study.

\section{Consent for publication}

Consent for publication obtained from participants.

\section{Competing interests}

The authors declare that they have no competing interests.

Received: 29 October 2019 Accepted: 17 March 2020

Published online: 30 March 2020

\section{References}

1. Johnell O, Kanis JA. An estimate of the worldwide prevalence and disability associated with osteoporotic fractures. Osteoporos Int. 2006:17(12):1726-33.

2. Wark JD. Osteoporosis: a global perspective. Bull World Health Organ. 1999; 77(5):424-6.

3. Cooper C, Campion G, Melton $L J$ 3rd. Hip fractures in the elderly: a worldwide projection. Osteoporos Int. 1992;2(6):285-9.

4. Chinese Health Promotion Society. Summary statement of osteoporosis white paper China 2008. Chin J Health Manag. 2009:3(3):148-54.

5. Haaland DA, Cohen DR, Kennedy CC, Khalidi NA, Adachi JD, Papaioannou A. Closing the osteoporosis care gap: increased osteoporosis awareness among geriatrics and rehabilitation teams. BMC Geriatr. 2009:9:28.

6. Shakil A, Gimpel NE, Rizvi H, Siddiqui Z, Ohagi E, Billmeier TM, Foster B. Awareness and prevention of osteoporosis among south Asian women. J Community Health. 2010;35(4):392-7.

7. Chan MF, Kwong WS, Zang YL, Wan PY. Evaluation of an osteoporosis prevention education programme for young adults. J Adv Nurs. 2007;57(3): 270-85.

8. Kung AW, Lee KK. Knowledge of vitamin D and perceptions and attitudes toward sunlight among Chinese middle-aged and elderly women: a population survey in Hong Kong. BMC Public Health. 2006;6:226.

9. Lee LY, Lai EK. Osteoporosis in older Chinese men: knowledge and health beliefs. J Clin Nurs. 2006;15(3):353-5.

10. Tung WC, Lee IF. Effects of an osteoporosis educational programme for men. J Adv Nurs. 2006;56(1):26-34.

11. Wong CP, Lok MK, Wun YT, Pang SM. Chinese men's knowledge and risk factors of osteoporosis: compared with women's. Am J Mens Health. 2014; 8(2):159-66.

12. Xu J, Sun M, Wang Z, Fu Q, Cao M, Zhu Z, Meng C, Yan Y, Mao J, Tao H, et al. Awareness of osteoporosis and its relationship with calcaneus quantitative ultrasound in a large Chinese community population. Clin Interv Aging. 2013;8:789-96. 
13. Nguyen NV, Dinh TA, Ngo QV, Tran VD, Breitkopf CR. Awareness and knowledge of osteoporosis in Vietnamese women. Asia Pac J Public Health. 2015;27(2):Np95-105.

14. Toh LS, Lai PS, Wu DB, Wong KT, Low BY, Anderson C. The development and validation of the osteoporosis prevention and awareness tool (OPAAT) in Malaysia. PLoS One. 2015;10(5):e0124553.

15. Hui SL, Zhou L, Evans R, Slemenda CW, Peacock M, Weaver CM, McClintock C, Johnston CC Jr. Rates of growth and loss of bone mineral in the spine and femoral neck in white females. Osteoporos Int. 1999;9(3):200-5.

16. Mein AL, Briffa NK, Dhaliwal SS, Price RI. Lifestyle influences on 9-year changes in BMD in young women. J Bone Miner Res. 2004;19(7):1092-8.

17. Recker RR, Davies KM, Hinders SM, Heaney RP, Stegman MR, Kimmel DB. Bone gain in young adult women. Jama. 1992;268(17):2403-8.

18. Phillipov G, Phillips PJ, Leach G, Taylor AW. Public perceptions and selfreported prevalence of osteoporosis in South Australia. Osteoporos Int. 1998;8(6):552-6.

19. Alexandraki Kl, Syriou V, Ziakas PD, Apostolopoulos NV, Alexandrakis Al, Piperi C, Kavoulaki E, Myriokefalitakis I, Korres G, Diamanti-Kandarakis E. The knowledge of osteoporosis risk factors in a Greek female population. Maturitas. 2008;59(1):38-45

20. Juby AG, Davis P. A prospective evaluation of the awareness, knowledge, risk factors and current treatment of osteoporosis in a cohort of elderly subjects. Osteoporos Int. 2001;12(8):617-22.

21. Monsanto HA. Level of awareness about osteoporosis among women 50 years and older in Puerto Rico. P R Health Sci J. 2010;29(1):54-9.

22. Saw SM, Hong CY, Lee J, Wong ML, Chan MF, Cheng A, Leong KH. Awareness and health beliefs of women towards osteoporosis. Osteoporos Int. 2003;14(7):595-601.

23. Matthews HL, Laya M, DeWitt DE. Rural women and osteoporosis: awareness and educational needs. J Rural Health. 2006;22(3):279-83,

\section{Publisher's Note}

Springer Nature remains neutral with regard to jurisdictional claims in published maps and institutional affiliations.

Ready to submit your research? Choose BMC and benefit from:

- fast, convenient online submission

- thorough peer review by experienced researchers in your field

- rapid publication on acceptance

- support for research data, including large and complex data types

- gold Open Access which fosters wider collaboration and increased citations

- maximum visibility for your research: over $100 \mathrm{M}$ website views per year

At $\mathrm{BMC}$, research is always in progress.

Learn more biomedcentral.com/submissions 